\title{
Behaviour of Retail Entrepreneurs
}

by

A. Roy Thurik and Johan Koerts*

\begin{abstract}
Retailers' goal attainment is studied using a model consisting of relationships concerning the productivity of labour and floorspace. Evidence from large supermarkets shows that retailers concentrate on the maximisation of the value of annual sales rather than on maximising annual profit.
\end{abstract}

\section{INTRODUCTION}

In this article we shall investigate whether retail entrepreneurs try to maximise the value of annual sales per establishment or to maximise their annual net profit. The former hypothesis is maintained in our previous studies on floorspace productivity where it is argued that this sales maximisation is achieved by adjusting the partitioning of total available floorspace into selling area and remaining space. Different partitioning is associated with different marketing or operational strategies. (See Thurik and Koerts [1984a: 387-445 and 1984b: 35-47].) It is explained in these studies that maximisation of the value of annual sales is equivalent to that of annual net profit provided that this partitioning does not affect cost factors or the average percentage gross margin. However, there are reasons to assume that it does. When this happens, the maximisation of the value of annual sales and that of annual net profit are no longer equivalent.

We shall discuss in this article to what extent the partitioning of total available floorspace influences cost factors and the average percentage gross margin. Consecutively, we shall present a model which will be used to test whether shopkeepers maximise the value of annual sales or that of annual net profit. This model primarily consists of relationships already discussed elsewhere. For our tests we use data from large French supermarket-type establishments, which are also used by Thurik [1984a: 19-29] in his study of labour productivity on the assumption that such establishments are large enough from a financial point of view to vary the partitioning of total floorspace with ease. Moreover, the construction of their building is often flexible enough to permit easy variation.

*This article is an adapted version of the concluding chapter of the first author's doctoral dissertation (Thurik [1984b]) defended at the Erasmus University. Rotterdam. in April 1984. In its published form it will later be reviewed in this Journal. 
We emphasise that the present study has a tentative character because

a) not all the influences on the partitioning of total available floorspace on cost factors and margin can be modelled;

b) results are presented for large retail establishments only.

Further study is needed to eliminate these drawbacks.

\section{MODEL}

A model will be developed which investigates entrepreneurial behaviour: whether retail entrepreneurs try to maximise the value of annual sales per establishments or that of annual net profit. This model consists primarily of relationships already discussed by Thurik and Koerts [1984a and 1984b] and Thurik [1984a]. Therefore, the present treatment will sometimes be brief.

Our considerations are based on the fact that total available floorspace of a retail establishment $i, W_{i}$, consists of selling area $C_{i}$ and remaining space $R_{i}$ :

$$
\mathrm{W}_{\mathrm{i}} \triangleq \mathrm{C}_{\mathrm{i}}+\mathrm{R}_{\mathrm{i}}
$$

It is the shopkeeper's task to establish the partitioning of the available space into selling areas and 'the rest'. This partitioning is determined by the marketing or operational strategy of an establishment. For example, a high share of remaining space is associated with

- a low share of self-service sales and a high share of counter service sales;

- a high share of own production

It is assumed that this partitioning influences

(i) floorspace productivity. Both selling area and remaining space are treated as inputs in a production technology for retail services.

(ii) labour productivity. A high share of self-service yields a higher labour productivity than a low share, ' because self-service is a mode of service in which the customers themselves perform a considerable amount of labour.

(iii) occupancy costs per unit of floorspace. These costs consists of two components: rent and remaining occupancy costs (energy, insurance, maintenance of inventory etc.). Average occupancy costs per unit of floorspace decrease if the share of remaining space increases, because selling area is more expensive than remaining space in terms of occupancy costs.

(iv) wage rate. A high share of remaining space (i.e. high share of counter service sales and/or a high share of own production) requires a high quality of labour. Consequently, the wage rate will be high

(v) average gross margin.: A high share of remaining space (i.e. high share of counter service sales and/or a high share of own produc- 
tion) is associated with a high added value in the distribution process of goods.

There are two distinct methods of establishing the partitioning depending what is assumed about retailers' behaviour. Our analysis should follow the lines set out in Thurik and Koerts [1984a and 1984b] if an entrepreneur tries to maximise the value of annual sales given total available floorspace: only assumption (i) must be taken into account. If, on the contrary, an entrepreneur tries to maximise the value of annual net profit, cost factors [assumptions (ii) to (iv)] and gross margin [assumption (v)] must also be taken into account.

It is the aim of this article to study entrepreneurial behaviour. To this end, we introduce an entrepreneurial goal function. This function contains a coefficient $\xi$ which should tell us whether retailers attempt to maximise sales or profit. This function should take into account that the total available floorspace of a retail establishment consists of selling area and remaining space. We therefore employ a Lagrangean function in which restriction $W_{i} \triangleq C_{i}+R_{i}$ appears with a multiplier." The Lagrangean goal function now reads:

$$
L F_{i}=\xi P_{i}+(1-\xi) Q_{i}+\lambda_{i}\left(W_{i}-C_{i}-R_{i}\right) \text { with } 0 \leqslant \xi \leqslant 1,
$$

where

$L F_{i}$ : value of the Lagrangean function per establishment $i$;

$P_{i}$ : value of annual net profit;

$Q_{i}$ : value of annual sales;

$\lambda_{i}$ :Lagrangean multiplier;

$\xi$ :coefficient which determines entrepreneurial behaviour: sales are maximised if $\xi=0$, and net profit if $\xi=1$.

It is difficult to draw conclusions if $\xi+0$ and $\xi+1$, because various causes may occur:

- some retailers maximise sales, whereas others maximise profit;

- a retailer may sometimes maximise sales and sometimes profit;

- retailers maximise neither sales nor profit, but pursue different goals, if any.

Now, given that

$$
P_{i} \triangleq M_{i} Q_{i}-K_{i}
$$

i.e. profits are equal to the average percentage gross margin multiplied by the value of annual sales less costs, and

$$
\mathrm{K}_{\mathrm{i}} \triangleq \mathrm{FL}_{\mathrm{i}} \mathrm{L}_{\mathrm{i}}+\mathrm{HV}_{\mathrm{i}} \mathrm{W}_{\mathrm{i}}+\mathrm{O}_{\mathrm{i}}
$$

*N.B, $F L_{i} L_{i}$ are total labour costs and $H V_{i} W_{i}$ are total occupancy costs. 
costs are equal to wage rate, times labour volume plus occupancy costs plus remaining costs

where

$M_{i}$ : average percentage gross margin divided by 100 for establishment $\mathrm{i}$;

$\mathrm{K}_{\mathrm{i}}$ : total annual costs;

$\mathrm{FL}_{\mathrm{i}}$ : wage rate;

$\mathrm{L}_{\mathrm{i}}$ : volume of labour;

$\mathrm{HV}_{\mathrm{i}}$ : occupancy costs per unit of floorspace;

$\mathrm{O}_{\mathrm{i}}$ : annual remaining costs;

then the assumptions mentioned above describe various ways in which the partitioning of total floorspace influences variables defined in the goal function.

To examine these variables in turn:

(i) value of annual sales, $\mathrm{Q}_{\mathrm{i}}$ :

$$
\left.\mathrm{Q}_{\mathrm{i}}=\beta_{\mathrm{i}}\left(\mathrm{C}_{\mathrm{i}}-\gamma_{1}\right)^{\pi \varepsilon}\left(\mathrm{R}_{\mathrm{i}}-\gamma_{2}\right)^{(1} 1-\pi\right) \varepsilon
$$

with $\beta_{\mathrm{i}}>0,0 \leqslant \gamma_{1}<\mathrm{C}_{\mathrm{i}}, 0 \leqslant \gamma_{2}<\mathrm{R}_{\mathrm{i}}, 0<\pi<1$ and $\varepsilon>0$.

See Thurik and Koerts [1984a and 1984b] for a detailed explanation of (5).

Specification (5) is chosen on the basis of the following arguments:

- differences in the value of annual sales per establishment in a certain shop type depend primarily on differences in the size of their floorspace;

- both selling area, $C_{i}$, and remaining space, $R_{i}$, contribute to the establishment of sales. These inputs can be substituted for one another. This substitution represents different marketing or operational strategies. For instance, self-service requires selling area instead of remaining space, and own production (bread-baking, butchering, repairs etc.) requires remaining space instead of selling area;

- coefficient $\beta_{\mathrm{i}}$ can be used to incorporate further influences on the efficiency of floorspace, which may differ among establishments (assortment composition. location etc.). An example is given in equation (A15) of the Appendix (see page 345);

- coefficient $\pi$ indicates the degree to which establishments of a certain shop type are selling area intensive;

- coefficients $\gamma_{1}$ and $\gamma_{2}$ are associated with threshold spaces: space which must be present in every establishment of a shop type, no matter how small its sales size;

Equation (5) models the supply side of the relation between sales and floorspace. Clearly. sales, and hence floorspace productivity, are deter- 
mined by the interplay of supply and demand, and cannot be analysed from the supply side alone. Kooiman et al. [1985] add an explicit demand side to the model. They conclude however that equation (5) is an acceptable approximation.

(ii) labour productivity, $\mathrm{L}_{\mathrm{i}}$,

$$
\mathrm{L}_{\mathrm{i}}=\alpha_{O}+\alpha_{1 i}\left(\frac{\mathrm{R}_{\mathrm{i}}}{\mathrm{W} 2 \mathrm{i}}\right)^{\alpha_{3}} \mathrm{Q}_{\mathrm{i}} \text { with } \alpha_{\mathrm{o}}>0 \text { and } \alpha_{1 \mathrm{i}}>0,
$$

where $\mathrm{L}_{\mathrm{i}}$ : volume of labour.

See Thurik [1984a] for an explanation of (6). A high share of remaining space (i.e. low share of self-service sales and/or high share of own production) results in a low labour productivity. ${ }^{+}$Therefore, it is assumed that $\alpha_{3}$ $>0$. See Nooteboom [1982: 163-86] for a detailed theoretical justification of the use of equation (6).

(iii) - (v) occupancy costs per unit of floorspace, $H V_{i}$; wage rate $F L_{i}$ and average percentage gross margin, $M_{i}$ :

These are functions of the partitioning of total floorspace. We have no experience concerning the specification of these relationships, as opposed to those between the partitioning of total floorspace and sales or labour productivity. It should also be clear that $\mathrm{HV}_{\mathrm{i}}, \mathrm{FL}_{\mathrm{i}}$ and $\mathrm{M}_{\mathrm{i}}$ cannot be functions of the partitioning only. For instance, occupancy costs will also be influenced by the attractiveness of the location and average percentage gross margin and by the assortment composition.

\section{DISCUSSION}

The model to estimate $\xi$ becomes quite complicated, if all theoretical influences of the share of remaining space are honoured in the test specifications. Moreover, we are not in a position to use knowledge already acquired for the explanation of $\mathrm{HV}_{\mathrm{i}}, \mathrm{FL}_{\mathrm{i}}$ and $\mathrm{M}_{\mathrm{i}}$.

Nevertheless some preliminary explorative exercises were performed. It appears that

a) no correlation can be found between wage rate and share of remaining space;

b) a small and insignificant correlation is found between occupancy costs per unit of floorspace and share of remaining space; ${ }^{5}$

c) average percentage gross margin can by no means be explained using the share of remaining space.

Additionally, remaining costs do not appear to be influenced by the share of remaining space which appears to influence scale-adjusted labour 
intensity, although not always significantly. The above results are obtained using samples not only of large French supermarket-type establishments, but also of small Dutch supermarkets. These results are obtained using single-equation regressions. This is a clear disadvantage, because the complete model is probably a multiple-equation model containing various simultaneous effects.

We exempted the influences on the share of remaining space through occupancy costs per unit of floorspace, wage rate and average percentage gross margin (assumptions (iii) - (v)) from our further exercises. We left them out of consideration rather than use them badly. Ideally, their influences should be taken into account. However, we have no sound theory concerning the nature of their influences. Explorative exercises do not show significant influences and moreover, we believe that, if there are any such influences, they are probably weak in the case of occupancy costs per unit of floorspace and wage rate. However, while we believe that there is certainly an influence in the case of average percentage gross margin, we failed to establish it, because we do not have a sound theory for the explanation of average percentage gross margin per establishment.

The omission of the influence of share of remaining space on average percentage gross margin may influence the results obtained. Therefore, the exercises in this article must be viewed as a preliminary orientation. The omission of occupancy costs per unit of floorspace as an endogenous variable has the advantage that it permits its use as an exogenous variable explaining differences in floorspace efficiency. (See equation (A15) in the Appendix, page 345.)

\section{TESTS}

Our full estimation model is discussed in the Appendix. The following hypotheses will be tested using the model consisting of equations (A.11)(A.13) of the Appendix:

$\mathrm{H} 1$ : retail entrepreneurs try to maximise the value of annual sales per establishment rather than that of annual net profit, i.e., $\xi=0$.

$\mathrm{H} 2$ : scale-adjusted labour intensity increases if the share of remaining space in total available floorspace increases, i.e., $\alpha_{3}>0$.

We choose to assume the maximisation of the value of annual sales instead of that of annual profit, because

- it is realistic. A shopkeeper will concentrate on sales or market share rather than profit, if he considers his market power towards customers and suppliers or if he considers his prestige. Furthermore, there are circumstances in which the continuity of a shop depends on the increase of sales rather than on that of profit.

- it is simple. Sales are an entity easy to observe continually, whereas profit is a result given, so to speak, by the auditor once a year. Furthermore, the problem of maximisation of the value of annual net 
profit is probably too complicated for shopkeepers who usually fail to have staff facilities. It involves not only the analysis of the explanation of sales, but also that of percentage margin and costs.

- the results obtained are encouraging (See Thurik and Koerts [1984a and 1984b].)

Scale-adjusted labour intensity (the inverse of productivity) equals $\left(L_{i}-\alpha_{O}\right) / Q_{i}=\alpha_{1 i}\left(R_{i} / W_{i}\right)^{\alpha_{3}}$, Compare equation (6). See Thurik [1984a:20] for an elucidation of this expression.

Our model is estimated for magasins populaires (MP7579), hypermarkets (HYP7577) and supermarkets (SUP7579). A definition of these shop types is given by Thurik [1984a:27], as well as the sources of the data and a description of some of the vectors used. A description of the remaining vectors can be found in Thurik [1984b:71].

The following conclusions can be drawn from Table 1 regarding $\mathrm{H} 1$ and H2 (per shop type two estimations are reported: one with $0 \leqslant \xi \leqslant 1$ and one with $\xi=1)$ :

H1: $\xi$ does not differ significantly from zero in all three cases. It tends to be zero for magasins populaires and supermarkets. The likelihood ratio test statistic $2[\mathrm{~L}(\xi=1)-\mathrm{L}]$ can be computed from Table 1 . This test statistic has asymptotically a $\chi^{2}$ - distribution with one degree of freedom. The hypothesis that shopkeepers try to maximise the value of annual net profit is rejected at a 5 per cent level of significance for magasins populaires and supermarkets. This hypothesis cannot be rejected for hypermarkets. In short, the hypothesis that entrepreneurs try to maximise the value of annual sales is supported for magasins populaires and supermarkets. No such conclusion can be drawn regarding hypermarkets.

$\mathrm{H} 2$ : $\hat{a}_{3}>0$ in all three cases if $\xi$ is not restricted and significantly for magasins populaires and supermarkets. For these types of shop the hypothesis is supported that labour intensity increases if the share of remaining space increases. Now, it is understandable that $\mathrm{H} 1 \mathrm{cannot}$ be tested (in the sense that no conclusion can be drawn) for hypermarkets, because labour intensity is not influenced by the share of remaining space. Therefore maximisation of value of annual sales is equivalent to maximisation of value of annual net profit.

In the light of the result that it cannot be rejected that $\xi=0$, it is obvious that the estimated coefficients in Table 1 show values and signs which are in accordance with those obtained by Thurik [1984a] in his anlaysis of labour productivity differences and by Thurik and Koerts [1984a] in their analysis of floorspace efficiency differences. Therefore, we shall review further results only briefly:

- average floorspace efficiency $\left(\beta_{O}\right)$ is higher for hypermarkets than for magasins populaires and supermarkets; 
TABLE 1

ESTIMATES OF COEFFICIENTS OF THE MODEL CONSISTING OF EOUATIONS (A.11). (A.12) AND (A.13).WITH (A.15) AND (A.16)

\begin{tabular}{|c|c|c|c|c|c|c|c|}
\hline \multirow{2}{*}{\multicolumn{2}{|c|}{$\begin{array}{l}\text { shop type } \\
\text { everage efficlency } \hat{B}_{0}\end{array}$}} & \multicolumn{2}{|c|}{ PP7579 } & \multicolumn{2}{|c|}{ HYP7577 } & \multicolumn{2}{|c|}{ SUP7579 } \\
\hline & & $\begin{array}{l}3.11 \\
(.03)\end{array}$ & $\begin{array}{l}3.08 \\
(.03)\end{array}$ & $\begin{array}{l}3.90 \\
(.13)\end{array}$ & $\begin{array}{l}3.90 \\
(.13)\end{array}$ & $\begin{array}{l}3.23 \\
(.04)\end{array}$ & $\begin{array}{l}3.22 \\
(.04)\end{array}$ \\
\hline occupancy costs & $\hat{B}_{1}$ & $\begin{array}{l}.496 \\
(.061)\end{array}$ & $\begin{array}{l}.495 \\
(.069)\end{array}$ & $\begin{array}{l}.581 \\
(.080)\end{array}$ & $\begin{array}{l}.581 \\
(.080)\end{array}$ & $\begin{array}{l}.480 \\
(.067)\end{array}$ & $\begin{array}{l}.480 \\
(.066)\end{array}$ \\
\hline threshold & $\gamma_{1}$ & $\begin{array}{l}.560 \\
(.029)\end{array}$ & $\begin{array}{l}.579 \\
(.020)\end{array}$ & $\begin{array}{l}2.16 \\
(.95)\end{array}$ & $\begin{array}{l}2.16 \\
(.90)\end{array}$ & $\begin{array}{l}.236 \\
(.053)\end{array}$ & $\begin{array}{l}.212 \\
(.056)\end{array}$ \\
\hline d1stribution & $\pi$ & $\begin{array}{l}.336 \\
(.026)\end{array}$ & $\begin{array}{l}.261 \\
(.044)\end{array}$ & $\begin{array}{l}.360 \\
(.030)\end{array}$ & $\begin{array}{l}.358 \\
(.028)\end{array}$ & $\begin{array}{l}.534 \\
(.028)\end{array}$ & $\begin{array}{l}.549 \\
(.025)\end{array}$ \\
\hline saleo elasticlty & $\bar{E}$ & $\begin{array}{l}.547 \\
(.053)\end{array}$ & $\begin{array}{l}.527 \\
(.048)\end{array}$ & $\begin{array}{l}.608 \\
(.068)\end{array}$ & $\begin{array}{l}.608 \\
(.069)\end{array}$ & $\begin{array}{l}.711 \\
(.062)\end{array}$ & $\begin{array}{l}.741 \\
(.063)\end{array}$ \\
\hline threshold & $a_{0}$ & $\begin{array}{l}8.30 \\
(4.07)\end{array}$ & $\begin{array}{l}-1.94 \\
(3.36)\end{array}$ & $\begin{array}{c}31.52 \\
(10.86)\end{array}$ & $\begin{array}{c}29.99 \\
(10.80)\end{array}$ & $\begin{array}{l}3.67 \\
(1.06)\end{array}$ & $\begin{array}{c}2.59 \\
(1.03)\end{array}$ \\
\hline foods 811 & $\hat{a}_{11}$ & $\begin{array}{l}2.85 \\
(.40)\end{array}$ & $\begin{array}{l}2.09 \\
(.09)\end{array}$ & $\begin{array}{l}.714 \\
(.053)\end{array}$ & $\begin{array}{l}.703 \\
(.049)\end{array}$ & $\begin{array}{l}2.10 \\
(.12)\end{array}$ & $\begin{array}{l}1.86 \\
(.07)\end{array}$ \\
\hline cl1 proportion & $\alpha_{1 r}$ & 2. & 2. & 4. & 4. & .5 & .5 \\
\hline wage rate & $a_{2}$ & $\begin{array}{l}-.777 \\
(.112)\end{array}$ & $\begin{array}{l}-.568 \\
(.079)\end{array}$ & $\begin{array}{l}-.929 \\
(.136)\end{array}$ & $\begin{array}{l}-.919 \\
(.144)\end{array}$ & $\begin{array}{l}-.652 \\
(.064)\end{array}$ & $\begin{array}{l}-.570 \\
(0.59)\end{array}$ \\
\hline remalniag space & $a_{3}$ & $\begin{array}{l}.815 \\
(.295)\end{array}$ & $\begin{array}{c}.091 \\
(.056)\end{array}$ & $\begin{array}{l}.040 \\
(.139) *\end{array}$ & $\begin{array}{l}.007 \\
(.123)\end{array}$ & $\begin{array}{l}.141 \\
(.069)\end{array}$ & $\begin{array}{l}-.013 \\
(.028)\end{array}$ \\
\hline goal & $\bar{\xi}$ & $\stackrel{.0}{(.313) \star}$ & 1 & $(22.801)$ & 1 & $\stackrel{.0}{(1.249) *}$ & 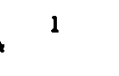 \\
\hline $\begin{array}{l}\text { aumber of } \\
\text { observatioas }\end{array}$ & I & 71 & 71 & 68 & 68 & 121 & 121 \\
\hline $\begin{array}{l}\text { neg.conc. } \\
\text { loglikelihood }\end{array}$ & $\mathbf{L}$ & 597.79 & 606.73 & 888.09 & 888.13 & 1012.58 & 1015.16 \\
\hline $\begin{array}{l}\text { goodness of fit } 1 \\
\text { 800dness of fit } 2 \\
\text { 800dness of f1t } 3 \\
\text { goodness of fit } 4\end{array}$ & $\begin{array}{l}\mathbf{r}^{2} \\
\mathbf{r}_{2}^{2} \\
\mathbf{r}^{2} \\
\mathbf{r}^{2}\end{array}$ & $\begin{array}{l}.67 \\
.75 \\
.56 \\
.85\end{array}$ & $\begin{array}{l}.63 \\
.92 \\
.54 \\
.84\end{array}$ & $\begin{array}{l}.75 \\
.92 \\
.68 \\
.87\end{array}$ & $\begin{array}{l}.75 \\
.92 \\
.68 \\
.87\end{array}$ & $\begin{array}{l}.72 \\
.94 \\
.88 \\
.86\end{array}$ & $\begin{array}{l}.72 \\
.92 \\
.88 \\
.85\end{array}$ \\
\hline $\begin{array}{l}\text { correlation of } \\
\text { residuals }\end{array}$ & $\mathbf{R}$ & $\begin{array}{r}.55 .41 \\
.85\end{array}$ & $\begin{array}{r}.18 .49 \\
.25\end{array}$ & $\begin{array}{rr}.02 & .22 \\
-.05\end{array}$ & $\begin{array}{r}-.01 \\
-.22 \\
-.11\end{array}$ & $\begin{array}{r}-.30 \\
.049 \\
.04\end{array}$ & $\begin{array}{r}-.49 .40 \\
-.28\end{array}$ \\
\hline
\end{tabular}

Note: the asymptotic distribution of the maximum likelihood estimates is assumed to be multivariate normal. Estimated stndard errors $(0)$ are printed beneath the estimated cocfficients. An asterisk $\left({ }^{*}\right)$ is printed next to the standard error of coefficient $\eta$ if $\eta<1.64$ $\sigma(\eta)$, i.c. if $\eta$ is not significantly different from zero at a $10 \%$ level of significance.

The square of the correlation coefficient between the vectors of the dependent variable and its estimation is taken as measure of goodness of fit: 1 refers to the antilog form of (A.11). 2 to (A.12). 3 to (A.13) and 4 to (A.14).

$R$ is the matrix of correlation coefficients between the vectors of residuals of equations (A.11) through (A.12):

$R=\left[\begin{array}{ll}r_{12} & r_{13} \\ - & r_{23}\end{array}\right]: 1$ refers to (A.11). $210(A .12)$ and 3 to (A.13). 
- the hypothesis is supported that floorspace efficiency increases if occupancy costs per unit of floorspace increase $\left(\beta_{1}>0\right)$;

- positive floorspace threshold coefficients $\left(\gamma_{1}\right)$ are found.

- supermarkets have the highest selling space intensity $(\pi)$;

- the hypothesis is supported that the asymptotic sales elasticity with respect to total available floorspace is less then one $(\varepsilon)$;

- positive labour threshold coefficients $\left(\alpha_{O}\right)$ are found.

- the hypothesis is supported that labour intensity decreases if the wage rate of the establishment increases $\left(\alpha_{2}>0\right)$;

- in the light of the simple model used, the explanation is fairly high for a cross-section model.

\section{CONCLUSIONS}

In this article a model is built to study the question whether retail entrepreneurs try to maximise the value of annual sales per establishment or that of annual net profit. This model comprises relationships already discussed in other studies. Its essence is that the partitioning of total floorspace into selling area and remaining space can be associated with the marketing or operational strategy and that this partitioning influences the value of annual sales, cost factors and average percentage gross margin.

The model was tested using samples of large French supermarket-type establishments. It appears that the hypothesis ( $\mathrm{H} 1)$ of maximisation of the value of annual sales cannot be rejected. This was a maintained hypothesis in other studies on the explanation of floorspace efficiency differences (Thurik and Koerts [1984a and 1984b]). It also appears that labour intensity increases if the share of remaining space in total floorspace increases ( $\mathrm{H} 2)$. It should be noted that the influence of the partitioning of total floorspace on average percentage gross margin is not established.

Further research on the explanation of average percentage gross margin is needed to provide more evidence to support $\mathrm{H} 1$. This research is also necessary to complete a full micro-economic model of retail behaviour. Such a model is being developed at the Research Institute for Small and Medium-Sized Businesses in the Netherlands where it will be used for performance diagnosis. 


\section{APPENDIX}

In this Appendix the first order conditions, the estimation model and the estimation procedure will be discussed briefly. Moreover, a further specification of $\beta_{i}$ and $\alpha_{1 i}$ from equations (5) and (6) will be given.

Substitution of (3), (4) and (6) into (2) gives

(A.1) $\quad L F_{i}=\xi\left(M_{i}-\alpha_{1 i}\left(\frac{R_{i}}{W_{i}}\right)^{\alpha_{3}} F_{i}\right) Q_{i}+(1-\xi) Q_{i}+\lambda_{i}\left(W_{i}-C_{i}-R_{i}\right)+$ constant. After substitution of (5) into (A.1), the first order conditions

$\frac{\delta L F_{i}}{\delta C_{i}}=\frac{\delta L F_{i}}{\delta R_{i}}=\frac{\delta L F_{i}}{\delta \lambda_{i}}=0$ give

(A.2) $\xi A_{i} \pi \varepsilon Q_{i}+(1-\xi) \pi \varepsilon Q_{i}=\lambda_{i}\left(C_{i}-\gamma_{1}\right)$;

(A.3) $\quad \xi A_{i}(1-\pi) \varepsilon Q_{i}+(1-\xi)(1-\pi) \varepsilon Q_{i}-B_{i} Q_{i}=\lambda_{i}\left(R_{i}-\gamma_{2}\right)$;

(A.4) $\quad W_{i}=C_{i}+R_{i}$,

where

(A.5) $\quad A_{i}=M_{i}-\alpha_{1 i}\left(\frac{R_{i}}{W_{i}}\right)^{\alpha_{3}} F L_{i}$

and

(A.6) $\quad B_{i}=\alpha_{1 i}\left(\frac{R_{i}}{W_{i}}\right)^{\alpha_{3}} F L_{i} \xi \alpha_{3}\left(\frac{R_{i}-\gamma_{2}}{R_{i}}\right)$.

Summation of (A.2) and (A.3) and application of (A.4) give

(A.7) $\quad \lambda_{i}=D_{i} Q_{i} /\left(W_{i}-\gamma_{i}-\gamma_{2}\right)$

with

(A.8) $\quad D_{i}=\xi A_{i} \varepsilon+(1-\xi) \varepsilon-B_{i}$.

Now, equation (A.7) is used to eliminate $\lambda_{i}$ from (A.2) and (A.3):

(A.9) $\quad C_{i}=\gamma_{1}+\left(W_{i}-\gamma_{1}-\gamma_{2}\right)\left[\xi A_{i} \pi \varepsilon+(1-\xi) \pi \varepsilon\right] / D_{i}$;

(A.10) $\quad \mathbf{R}_{i}=\gamma_{2}+\left(W_{i}-\gamma_{1}-\gamma_{2}\right)\left[\xi A_{i}(1-\pi) \varepsilon+(1-\xi)(1-\pi) \varepsilon-B_{i} j / D_{i}\right.$.

We are not able to show whether equations (A.9) and (A.10) have a solution, nor whether there is one or more than one solution. Hence, we are not able to show whether a possible stationary point defined by (A.9) and (A.10) refers to a maximum.

However, on the basis of the estimation exercises we believe that equations (A.9) and (A.10) have one solution which refers to a maximum, because

- our maximisation routine always finds an optimum value of the coefficient vector:

- using different but realistic initial values of the coefficient vector, either the same optimum value is found or the routine diverges into an irrelevant area.

We now consider the model consisting of equations (5), (6), (A.9) and (A.10). 
Endogenous variables are $Q_{i}, L_{i}, C_{i}$ and $R_{i}$, whereas $W_{i}$ is exogenous. The vector of coefficients occurring in these equations is called $\theta$ with $\theta^{\prime}=\left(\beta_{i} \gamma_{1} \gamma_{2} \pi \varepsilon \alpha_{1}\right) \alpha_{1 i}$ $\left.\alpha_{3} \xi\right)$.

The restrictions on these coefficients are given in our discussion of equations (2), (5) and (6). Coefficients $\beta_{i}$ and $\alpha_{1 i}$ are assumed to depend on specific properties of the establishment. This will be explained in the section dealing with the test results.

The next part of this Appendix is devoted to the estimation of the coefficient vector $\theta$. Taking the logarithms in (5) and specifying an additive disturbance structure we obtain

$$
\log Q_{i}=\log \beta_{i}+\pi \varepsilon \log \left(C_{i}-\gamma_{1}\right)+(1-\pi) \varepsilon \log \left(R_{i}-\gamma_{2}\right)+\omega_{1} ;
$$

$$
L_{i}=\alpha_{0}+\alpha_{1 i}\left(\frac{R_{i}}{W_{i}}\right)^{\alpha_{3}} Q_{i}+v_{2 i}
$$

$$
\begin{aligned}
& \mathbf{C}_{i}=\gamma_{1}+\left(W_{i}-\gamma_{1}-\gamma_{2}\right)\left\{\left[\xi A_{i} \pi \varepsilon+(1-\xi) \pi \varepsilon\right] / D_{i}\right\}+v_{3 i} \\
& \mathbf{R}_{i}=\gamma_{2}+\left(W_{i}-\gamma_{1}-\gamma_{2}\right)\left\{\left[\xi A_{i}(1-\pi) \varepsilon+(1-\xi)(1-\pi) \varepsilon-B_{i}\right] / D_{i}\right\}+v_{4 i}
\end{aligned}
$$

It should be noted the $\mathrm{v}_{3 \mathrm{i}}+\mathrm{v}_{4 \mathrm{i}}=0$ in equations (A.13) and (A.14). Therefore, one of these equations can be deleted in our estimation procedure. We choose to leave out (A.14). Barten [1969:7-73] proves that for obtaining maximum likelihood estimates it does not matter which one is omitted, if the singularity occurs in a complete system of equations with a disturbance vector having a multivariate normal distribution. The same result is valid for a subset of a system of equations. See Kooiman [1982].

We now define $V_{i}$ with $V_{i}{ }^{\prime}=\left(v_{1 i} v_{2 i} v_{3 i}\right)$. We assume that $V_{i} \sim N(0, \Omega)$ for $i=1$, $\ldots, \mathrm{I}$ : trivariate normal distribution with zero means and constant, positive definite and symmetric covariance matrix

$$
\Omega=\left[\begin{array}{lll}
\omega_{11} & \omega_{12} & \omega_{13} \\
\omega_{21} & \omega_{22} & \omega_{23} \\
\omega_{31} & \omega_{32} & \omega_{33}
\end{array}\right] .
$$

In addition, it is assumed that $E\left(V_{i} V_{i}{ }^{\prime}\right)=0$ for $i \ddagger i$.

Full information maximum likelihood estimates are found by locating a maximum of the likelihood function with respect to $\theta$ after concentrating this function with respect to $\Omega$. The numerical maximisation is performed by the variable metric method of Broyden, Fletcher, Goldfarb and Shanno.

The model consisting of equations (A.11)-(A.13) is further specified in the following manner:

$$
\beta_{i}=\beta_{01}\left(\frac{H V_{i}}{\bar{H} \bar{V}}\right)^{\beta_{1}}
$$

and

$$
\alpha_{1 i}=\alpha_{11}\left(\frac{Q_{1 i}}{Q_{i}}+\alpha_{1 r} \frac{Q_{2 i}}{Q_{i}}\right)\left(\frac{F L_{i}}{\bar{F} \dot{L}}\right)^{\alpha i}
$$


The definition of all the variables used now becomes

$W_{i}$ : total available floorspace for foods and non-foods of establishment $i$ (in $\left.10^{3} \mathrm{~m}^{2}\right)$

$C_{i}$ : selling area of foods and non-foods (in $10^{3} \mathrm{~m}^{2}$ );

$\mathbf{R}_{\mathbf{i}}$ : remaining space (in $10^{3} \mathrm{~m}^{2}$ );

$Q_{1 i}$ : value of annual sales of foods (in $10^{6}$ French francs of 1979);

$\mathrm{Q}_{2 \mathrm{i}}$ : value of annual sales of foods (in $10^{6} \mathrm{FF}$ of 1979);

$\mathrm{Q}_{\mathrm{i}} \triangleq \mathrm{Q}_{1 \mathrm{i}}+\mathrm{Q}_{2 \mathrm{i}}$

$\mathrm{L}_{\mathrm{i}}$ : volume of labour (in full-time equivalents);

$\mathrm{HV}_{\mathrm{i}}$ : total non-labour costs per $\mathrm{m}^{2}$ (in $10^{6} \mathrm{FF}$ of 1979). This variable is a proxy variable for occupancy costs per $\mathrm{m}^{2}$, which is not available;

$\mathrm{FL}_{i}$ : wage rate per man year (in $10^{6} \mathrm{FF}$ of 1979);

$\bar{H} \bar{V}$ and $\bar{F} \bar{L}$ : sample averages.

Some comments with respect to equations (A.15) and (A.16) are necessary:

- $\beta_{0}$ is a measure of the 'average' efficiency of floorspace;

- $\beta_{1}$ is the elasticity of $\beta_{i}$ with respect to $H V_{i} / \bar{H} \bar{V}$. It is assumed that firstly, rent price per unit of floorspace is an indicator of the environmental attraction of the establishment (occupancy costs consist mainly of rent) and secondly, the motivation to use available floorspace efficiently is induced by the height of occupancy costs per unit of floorspece. See Nooteboom [1980: 204-209];

- For simplicity, other influences on $\beta_{i}$ are deleted. See Thurik and Koerts [1984a] for a discussion of these influences;

- $\alpha_{11}$ is the partial 'average' scale-adjusted labour intensity (s/i) for food sales;

- $\alpha_{1 \mathrm{r}}=\alpha_{12} / \alpha_{11}$ where $\alpha_{12}$ is the partial 'average' scale-adjusted labour intensity of non-food sales. For simplicity an a priori value of $\alpha_{1 \mathrm{r}}$ is used, which is based on the estimations reported in Thurik [1984a: 23] [6]:

- $\alpha_{2}$ is the elasticity of $\alpha_{1 i}$ with respect to $F L_{i} / \bar{F} \bar{L}$. It is assumed that firstly, the wage rate per establishment is an indicator of the quality of labour and secondly, that the motivation to use available labour efficiently is induced by the height of the wage rate;

- For simplicity, other influences on $\alpha_{1 i}$ are deleted. See Thurik [1984a: 21] for a discussion of these influences.

Also, as in Thurik and Koerts [1984a], the remaining space threshold is assumed to be zero: $\gamma_{2}=0$. 


\section{NOTES}

1. See Bates [1976:55], Dawson and Kirby [1979:98], Henksmeier [1960:83 ff]. McClelland [1966:80] and Ward [1973:49].

2. Gross margin equals total revenue from annual sales minus total annual acquisition costs (= wholesale or invoice costs).

3. Knowledge of Lagrangean functions is not required for a good understanding of this article. For interested readers we refer to textbooks in advanced mathematics for economists. For instance, see Intriligator [1971:28 ff].

4. See Thurik and Van Schaik [1984], who study differences in average labour productivity among shop types in the retail trade in the Netherlands and who report that average labour productivity decreases if the average share of remaining space increases.

5. However, it appears that occupancy costs per unit of floorspace decrease with increasing total floorspace.

6. The a priori value of $\alpha_{1 r}$ for hypermarkets should be 2 if the estimates of Thurik [1984a:23] are considered. However, a value of 4 is used in the present article owing to a different definition of the assortment groups.

\section{REFERENCES}

Barten, A.P., 1969, 'Maximum Likelihood Estimation of Complete Systems of Demand Equations', European Economic Review, Vol.1.

Bates, P., 1976, The Independent Grocery Retailer, Report No.23, Manchester: Retail Outlets Research Unit, Manchester Business Schoot.

McClelland, W.G., 1966, Costs and Competition in Retailing, London: Macmillan.

Dawson, J.A. and D.A. Kirby, 1979, Small Scale Retailing in the U.K., Farnborough: Saxon House.

Henksmeier, K.H.. 1969, The Economic Performance of Self-service in Europe, Paris: Organization for European Economic Cooperation.

Intriligator, M.D., 1971, Mathematical Optimization and Economic Theory, Englewood Cliffs: Prentice Hall.

Kooiman. P., 1982, Using Business Survey Data in Empirical Disequilibrium Models, Paper 82/41, London: International Centre for Economics and Related Disciplines, London School of Economics.

Kooiman. P., H.K. van Dijk and A.R. Thurik, 1985, 'Likelihood Diagnostics and Bayesian Analysis of a Micro-economic Disequilibrium Model for Retail Services'. Journal of Econometrics Vol.29. Nos. 1/2.

Nooteboom, B., 1980, Retailing: Applied Analysis in the Theory of the Firm. Uithoorn/ Amsterdam: Gieben.

Nooteboom, B., 1982, 'A New Theory of Retailing Costs', European Economic Review, Vol.17.

Thurik, A.R., 1984a, 'Labour Productivity, Economies of Scale and Opening Time in Large Retail Establishments', Service Industries Journal, Vol.4, No.1.

Thurik, A.R., 1984b, Quantitative Analysis of Retail Productivity, Delft: Meinema.

Thurik. A.R. and J. Koerts, 1984a, 'On the Use of Supermarket Floorspace and its Efficiency', in The Economics of Distribution. Milan: Franco Angeli Editore.

Thurik. A.R. and J. Koerts, 1984h, 'Analysis of the Use of Retail Floorspace', International Small Business Journal, Vol.4. No.1.-

Thurik. A.R. and H.A.C. van Schaik, 1984, 'Gegeneraliseerde Kostenrelaties in de Detailhandel', Maandblad voor Accoumancy en Bedrijfshuishoudkunde, No.5.

Ward, T.S., 1973. The Distribution of Consumer Goods: Structure and Performance. London: Cambridge University Press. 
Copyright of Service Industries Journal is the property of Taylor \& Francis Ltd. The copyright in an individual article may be maintained by the author in certain cases. Content may not be copied or emailed to multiple sites or posted to a listserv without the copyright holder's express written permission. However, users may print, download, or email articles for individual use. 